\title{
К ПРОБЛЕМЕ СОЗДАНИЯ УНИВЕРСАЛЬНОГО УЧЕБНИКА ПО ИНОСТРАННОМУ ЯЗЫКУ ДЛЯ ВОЕННОСЛУЖАЩИХ (на примере учебника по русскому языку)
}

\author{
доц. др. Лект. Елена Казимианец, доц. др. Дилета Ятаутайте \\ Литовская военная академия имени генерала Йонаса Жямайтиса
}

\begin{abstract}
Резюме. В статье рассматривается проблема написания специализированного пособия для конкретной изелевой группы, такой как военные. Цель статьи - определение концептуальной платформы в создании современного учебного пособия нового поколения по русскому языку для военнослужащих, определение специфики его содержания. В задачи исследования также входит определение объёма и принципов отбора учебного материала, в частности лингвокультурологического, обеспечивающеге адекватное общение на русском языке. Исследование основано на описательно-аналитическом методе.
\end{abstract}

Исследование включает в себя множество вопросов, связанных с лингвистическими особенностями разработки пособия. Так, учебник по русскому языку для военнослужащих должен обеспечить формирование у учащихся целого ряда компетенций, связанных с владением устной и письменной речью, которые объединяются в общую коммуникативную компетенцию. Коммуникативная компетенция базируется на приобретенных в процессе обучения знаниях, умениях и навыках, обеспечивающих возможность участия в речевом общении в различных его видах: рецептивном (аудирование, чтение) и продуктивном (говорение, письмо). Таким образом, содержание коммуникативной компетенции состоит из следующих видов компетенции, таких как лингвистическая (языковая) компетенция, которая подразумевает совокупность знаний об элементах языка и умение использовать их для выражения отдельных мыслей и их осмысления другими людьми. Все эти виды компетенции необходимо учитывать при создании учебников, учебных пособий и методических пособий, предназначенных для обучения русскому языку военнослужащих. Следовательно, все тексты, задания и материалы, представленные в них, должны быть направлены на формирование всех вышеперечисленных компетенций. Естественно, что материал, помещенньй в учебник, должен быть многоуровневым - помимо чисто лингвистической информациии он должен содержать лингвокультурные, социальные, профессиональные и т.д. аспекты.

Ключевые слова: коммуникативная, речевая, сочииокультурная, лингвистическая компетенция, концептуальные подходы, семьи языков, военные 


\section{Введение}

Современное понимание сущности языка включает в себя не только осознание языка как средства коммуникации, познания, хранилища информации и человеческого опыта, но и восприятие языка как своеобразного кода нации. Язык по своей сути представляет собой сложнейшее явление, подобно зеркалу отражающее все стороны жизни человека, нюансы его сознания (мышления), психики, культурной памяти. Ю.С. Степанов попытался представить этот сложнейший феномен в виде совокупности нескольких образов:

- Язык как член семьи языков;

- Язык как структура;

- Язык как язык индивида;

- Язык как система;

- Язык как тип и характер;

- Язык как компьютер.

Язык как результат сложной когнитивной деятельности, то есть как пространство мысли или как «дом духа». В этом смысле язык представляет собой не только результат деятельности народа - носителя данного языка, но и не в меньшей степени является продуктом деятельности творческой личности. Сюда также следует включить плоды деятельности нормализаторов языка: государства, институтов, вырабатывающих нормы и правила (Маслова,2001, 6).

Более того в последние десятилетия к вышеперечисленным образам добавляется ещё один образ - язык как продукт культуры, её важнейшая составляющая часть и условие её существования. И, если понимать культуру в широком смысле, то следует почеркнуть, что в последнее десятилетие в условиях информационных и гибридных войн усиливается политическая составляющая языка как инструмента влияния на сознание людей.

Положение о том, что иностранный язык усваивается вместе с культурой чужой нации, признаётся сейчас всеми методистами. Напомним, что учёт лингвокультурологического и страноведческого компонента в преподавании иностранных языков является одним из трёх основных принципов современной лингводидактики, поэтому проблема отбора и предъявления культурологической информации стоит в центре внимания всех, кто занимается преподаванием русского языка в нерусской аудитории (Гранатовска, 1997, 49). В первую очередь это касается составителей учебных программ, авторов учебников и учебных пособий и, безусловно, самих преподавателей русского языка, так как именно от них зависит способ осуществления данного принципа в учебном процессе. Учебные пособия, учебные программы, предназначенные для обучения военных, должны, базируясь на новейших достижениях дидактической науки, иметь свою специфику, обусловленную профессиональной принадлежностью аудитории и задачами, стоящими перед преподавателем русского языка на конкретном этапе обучения. 
Объектом исследования данной статьи является лингвометодические параметры преподавания русского языка в военной аудитории.

Цель статьи - определение концептуальной платформы в создании современного учебного пособия нового поколения по русскому языку для военнослужащих, определение специфики его содержания. В задачи исследования также входит определение объёма и принципов отбора учебного материала, в частности лингвокультурологического, обеспечивающего адекватное общение на русском языке.

Исследование основано на описательно-аналитическом методе.

\section{Основная часть}

Постоянные изменения, происходящие в мире и обществе, характеризующиеся ярко выраженной тенденцией к ускорению ритма жизни, расширению всевозможных контактов представителей разных лингвокультурных сообществ благодаря технологизации и компьютеризации всех сфер деятельности современного человека, нашли своё отражение в методике преподавания иностранных языков. Появились новые концептуальные подходы к обучению РКИ, опирающиеся, с одной стороны, на лингвокультурологическую концепцию в методике, а с другой, основывающиеся на коммуникативно-прагматическом подходе к обучению. согласно которому особое внимание уделяется взаимодействию обучаемых и обучающих, и на принципе антропоцентризма, позволяющем сфокусировать внимание на формирование у обучаемых черт вторичной языковой личности. Такая постановка вопроса, по сути, и определяет сегодняшние перспективы и задачи теории учебных пособий по РКИ, в частности, пособий, предназначенных к использованию в военной аудитории, Следует отметить, что в случае преподавания русского языка военным, к учебным материалам (в том числе учебникам и пособиям) предъявляется ряд дополнительных требований. На первый план выдвигается задача обеспечения обучаемых необходимыми знаниями не только для адекватной коммуникации на бытовом и межкультурном уровне, но и для успешного осуществления их профессиональной деятельности на русском языке в различных ситуациях делового общения.

Таким образом, учебное пособие по русскому языку для военнослужащих должно обеспечить создание у обучаемых целого ряда компетенций, относящихся к владению устной и письменной речью, объединяемых в общую коммуникативную компетенцию. В основе коммуникативной компетенции лежат приобретённые в ходе обучения знания, навыки и умения, обеспечивающие возможность участвовать в речевом общении в разных его видах: рецептивных ( слушание, чтение) и продуктивных (говорение, письмо). По мнению А.Н. Щукина, содержание коммуникативной компетенции составляют следующие виды компетенций (на наш взгляд, необходимых военнослужа- 
щим): лингвистическая (языковая) компетенция, которая подразумевает совокупность знаний о единицах языка и умение такими единицами пользоваться для выражения своих мыслей и понимания мыслей других людей; речевая компетенция предполагает знание способов выражения мыслей с помощью языковых средств, что даёт возможность организовать и осуществить речевое действие (реализовать коммуникативное намерение) и тем самым понимать мысли других людей и выражать собственные в устной и письменной форме в различных ситуациях общения (в том числе профессионального); социокультурная компетенция (межкультурная, лингвокультурологическая) подразумевает знание национально-культурных особенностей страны изучаемого языка, правил речевого и неречевого поведения в типичных ситуациях общения, особенностей этикета носителей языка и умение координировать своё речевое поведение в соответствии с этими знаниями (Щукин, 2008. 17-19). Кроме того, в понятие коммуникативной компетенции можно включить и социальную компетенцию (желание и умение вступать в коммуникацию с другими людьми, дискурсивную компетенцию (знание правил построения связного устного и письменного сообщения - дискурса), предметную и стратегическую компетенцию (умение выбрать наиболее эффективные способы овладения материалом и использования его при решении коммуникативных задач). Все эти виды компетенций необходимо учитывать в ходе создания учебников, учебных книг и пособий, предназначенных для обучения русскому языку военных. Следовательно, все тексты, задания и материалы, представленные в них, должны быть направлены на создание всех вышеупомянутых компетенций. Естественно, материал, помещённый в учебной книге должен быть многослойным содержать помимо чисто языковой информации, лингвокультурологический, социальный, профессиональный и др. аспекты. Думается, что формирование лингвокультурологической компетенции является наиболее трудной задачей, стоящей перед создателями учебных пособий по русскому языку для военных, ибо создание объективного и политически нейтрального образа русской культуры требует от авторов тщательного и вдумчивого отбора информации и материалов, используемых в качестве учебных. Напомним, что лингвокультурологическая компетенция, в общем, проявляется в следующем:

- В умении констатировать сходства и различия между родной культурой и культурой народа изучаемого языка;

- В понимании точки зрения людей иного этнокультурного социума и свойственного им образа и стиля жизни;

- В объективизации образа родной культуры, традиций, способов ментально-языковой концептуализации действительности, сдержанности в проявлении эгоцентрических склонностей и в правозащитной позиции по отношению к родной культуре;

- В умении справляться в ситуациях межкультурных и межэтнических противоречий и недоразумений приемлемыми способами (Возьневич, 1998; 
Kazimianec, Jatautaitè, 2019).

Таким образом, перед авторами учебных пособий по РКИ, предназначенным для военнослужащих, стоит задача создания в учебном пособии необходимого минимизированного культурологического фона. В связи с этим материалы учебного пособия должны обеспечить работу в нескольких направлениях, в частности, постижение комплекса концептов, составляющих культурный фон языка, причём основное внимание следует уделять следующему:

- Изучению слов и выражений, представляющих предмет зучения лингвострановедения - слова и выражения типа у чёрта на куличках, баня, борщ, самогон и под. Сюда же можно отнести слова и фразеологизмы, рождённые в советский период: комсомол, трудовые победы, передавать эстафету, соцсоревнование, процесс пошёл и под., а также цитации из русской классики, типа: Маниловы, человек в футляре и др.

- Изучению безэквивалентных языковых единиц - слов и фразеологизмов, представляющих собой обозначения специфических для русской культуры явлений: пионер, перестройка, пионерский отряд, сбор металлолома, бессмертный полк, бить челом. Эти слова и выражения являются продуктом коммулятивной функции языка (т.е. накопительной, закрепляющей опыт носителей языка). Они могут рассматриваться как вместилище фоновых знаний, имеющихся в сознании говорящих.

- Изучению мифологизированных языковых единиц: архетипов и мифологем, обрядов, поверий, ритуалов, обычаев, закреплённых в языке. Напомним, что мифологема - это важный для мифа персонаж, который может переходить из мифа в миф. Например, русские Баба Яга, Кощей Бессмертный, Иванушка-дурачок и под. Архетип - это устойчивый образ, повсеместно возникающий в индивидуальном сознании людей и имеющий распространение в культуре. В этом смысле мифология - это хранилище архетипов, некое «общее для носителей языка знание», например, хлеб в русском языке имеет значение архетипа «символ (основа) жизни», «благополучия», «достатка» в выражениях есть чужой хлеб, хлебом не корми, поделиться последней коркой хлеба и др. (Маслова, 2001.102).

- Изучению пословиц и поговорок, поскольку большинство пословиц - это воплощение стереотипов народного сознания: Не подмажешь - не поедешь; семеро одного не ждут. Именно изучение фразеологического фонда языка даёт непосредственное представление о культуре и менталитете народа, поскольку во фразеологизмах хранятся представления народа о привычках, морали, поведении, обычаях, стереотипных для данного языкового сообщества образах: семь раз отмерь - один отрежь; дорога ложка к обеду, а яйцо ко Христову дню и под.

- Изучению эталонов, стереотипов, символов. Например, эталонами являются выражения типа грязный как свинья, голодный как волк, устал как собака, упрямый как осёл. Эталоном по сути могут быть любые выражения, 
являющиеся результатом национально-типического соизмерения мира, и таким образом, эталон представляет собой проявление нормативных представлений об, явлениях природы, общества, о человеке, о его качествах и свойствах. Примером символа может служить символика цветов, которая не совпадает у разных народов.

- Изучению метафор и образов.

- Изучению стилистического уклада русского языка, то есть соотношению диалектов, стилистической дифференциации.

- Изучению речевого поведения, то есть поведения, закреплённого в номинативных единицах, в единицах грамматических и стилистических.

- Изучению русского речевого этикета, включая военный речевой этикет, так как этикетные отношения это универсалия, проявления которой национально-специфичны (Казимянец, 2004, 330).

- И наконец, особое внимание следует уделить изучению русского национального менталитета. Относительно России принято считать, что её история, а следовательно, и характер русского народа - это неразгаданная тайна, которую трудно, а может быть, и невозможно понять и познать при помощи каких-то привычных схем, общепринятых доктрин, формул и учений. Неслучайно образ России у разных писателей, журналистов, политиков представлен по-разному. Одни считают русский народ трудолюбивым тружеником, создателем прекрасных произведений культуры, гостеприимным хозяином, другие, наоборот, отсталым и ни на что не способным, агрессивным, грубым и пьющим. Поэтому не так легко подобрать материалы, позволяющие создать у обучаемых объективный образ России и русского менталитета. По-видимому, здесь предпочтение следует отдать тщательно подобранным текстам. Именно в ходе изучения конкретного текста можно говорить и о положительных, и об отрицательных чертах русского характера, а также рассуждать о факторах, повлиявших на их формирование (Казимянец, 2004; Kazimianec, Jatautaitè, 2017).

Целесообразно определить критерии отбора единиц культурологического знания для репрезентации русской культуры в педагогических целях, в частности в учебниках и пособиях по русскому языку для военной аудитории. Думается, что критерии, предложенные В. Возьневичем, могут служить основой для разработки коцептуального подхода к данной проблеме.

Во-первых, в учебниках прежде всего должны учитываться те культурные реальности, которые характеризуются межэтнической общностью или сходством. Это располагает к положительному восприятию иноэтнической культуры.

Во-вторых, следует учитывать, прежде всего, те реальности культуры, которые при правильном содействии преподавателя «имеют шансы» вписываться и запечатлеваться в психике обучающихся. Здесь необходимо учитывать временную перспективу построения репрезентации русской культуры в 
ходе учебного процесса. Это предполагает, что реальности культуры прошлого, как бы ценны они ни были, учитываются в содержании обучения настолько, насколько они могут вписываться в познавательную активную деятельность учащихся перспективе настоящего - будущего.

В-третьих, из огромного богатства русской культуры следует отбирать те её реалии, которые в настоящее время в контексте актуальной жизни народа, развития государства, дилемм будущего особо актуализируются в сознании русского общества, находят отражение в общественном мнении, являются показателями национального тождества. Этот критерий можно как критерий современности.

В-четвёртых, отбор фактов реальной русской культуры для работы в аудитории касается аксиологической интерпретации этих реальностей. Аксиологическая интерпретация - это всегда проблема оценки и отношения к тем или иным реальностям, ибо в культурном наследии России (равно как и в наследии других наций) имеются реальности, которые вызывают разноречивые оценки (Возьневич, 1998; Jatautaite, Kazimianec, 2018).

\section{Выводы}

Подводя итог вышесказанному, приходим к следующим выводам.

- Современные учебные пособия по РКИ для военнослужащих должны носить полиформатный характер. Это даёт возможность постижения русского языка во всём его многообразии с учётом профессиональных потребностей обучаемых и с целью создания у них общей коммуникативной компетенции.

- В учебнике помимо чисто языковых фактов: необходимого лексического наполнения, соответствующего заданному языковому уровню и содержащему как общеупотребительную, так и профессиональную военную лексику, грамматики, заданий, направленных на развитие всех видов речевой деятельности, - должен содержаться определённый минимизированный культурологический фон.

- Отбор культурологического и страноведческого материала рекомендуется проводить на основе разработанных в статье критериев, в первую очередь связанных с актуальностью представленной в учебнике информации как для носителей языка, так и для самих обучаемых в контексте современной реальности.

- Создание такого культурологического фона целесообразно осуществлять на материале тщательно подобранных текстов разной стилистической и жанровой принадлежности, так как необходимым условием для включения в учебное пособие культурологической информации является её нейтральность и объективность. Необходимо также включать в учебники по РКИ для военнослужащих прецедентные тексты, которые хорошо известны носителям русского языка и постоянно используются в языковом употреблении. Такие тек- 
сты значимы в познавательном и эмоциональном отношении, они повышают мотивацию учащихся к изучению русского языка. Ценным лингвокультурологическим ресурсом в этом случае могут выступать аутентичные видеоматериалы и текстовые приложения к ним, представленные в качестве тематического дополнения к учебному пособию.

- И наконец, следует отметить, что современный учебник русского языка для военнослужащих, включающий лингвокультурологический аспект, должен также учитывать национальный характер адресата, так как подлинное понимание иной культуры осуществляется только в условиях диалога культур.

\section{Литература}

Возьневич В. (1998) Изучение иностранного языка как процесс постижения иноэтнической культуры // Studia Rossica Posnaniensia XXVII. Poznac.C.159-166.

Гранатовска Х. К вопросу об отборе и предъявлении культурологической информации в современном учебнике русского языка для поляков // Новое в теории и практике описания и преподавания русского языка. Варшава, 1997, - с.49-54.

Jatautaite, D., Kazimianec, J. (2018) The importance of sustaining secure ambience for cadets of the Military academy of Lithuania via balancing emotions and perception in attaining accelerated second language learning and acquisition // Journal of security and sustainability issues. Vilnius: Generolo Jono Žemaičio Lietuvos karo akademija. ISSN 2029-7017. (Scopus Sources).

Казимянец Е. К (2004). проблеме создания лингвокультурологического фона в школьных учебниках по русскому языку // Meninis tekstas: suvokimas, analizè, interpretacija. Vilnius, Nr.4. - p.327-334.

Kazimianec, J., Jatautaitè, D. (2019). Пособие по русскому языку для военнослужащих: Rusų kalbos mokomoji knyga kariams : (продвинутый этап обучения) : учебная книга / Елена Казимянец, Дилета Ятаутайте; Литовская военная академия имени генерала Йонаса Жямайтиса. Вильнюс: Литовская военная академия имени генерала Йонаса Жямайтиса, 1-301 р.

Kazimianec, J.,Jatautaite, D. (2017). Ответы к учебной книге «Путешествие в Россию» =: Mokomosios knygos "Kelionè į Rusiją" užduočių atsakymai : практический курс русского языка (продвинутый этап) : приложение к учебной книге / Елена Казимянец ; Литовская военная академия имени генерала Йонаса Жямайтиса. 2017. Вильнюс : Generolo Jono Žemaičio Lietuvos karo akademija, 123 p.

Маслова В.А. (2001). Лингвокультурология.- Москва.

Щукин А.Н. (2008). Компетенция и компетентность. Взгляд методиста на актуальную проблему лингводидактики // Русский язык за рубежом. N5 (210). Москва. - С.14-20. 


\title{
THE PROBLEM OF CREATING A UNIVERSAL MANUAL FOR THE MILITARY (The Case of the Russian Language Manual)
}

\author{
Lecturer, Assoc. Prof. Dr. Jelena Kazimianec, \\ Assoc. Prof. Dr. Dileta Jatautaitė \\ General Jonas Žemaitis Military Academy of Lithuania
}

\section{Summary}

The article scrutinizes the problem of writing a specialized manual for a particular target group such as the military. The aim of the article is to determine the conceptual platform for the creation of a new-generation Russian language manual for military personnel, and to determine the specifics of its content. The objectives of the study also include determining the scope and principles of the selection of teaching material, in particular linguocultural, which ensures adequate communication in Russian. The research is based on the descriptiveanalytical method.

Translated with www.DeepL.com/Translator (free version)It comprises many issues that are related to the linguistic particularities of designing a manual. Thus, a textbook on the Russian language for military personnel should ensure that students develop a whole range of competencies related to oral and written language proficiency, which are combined into a general communicative competence. Communicative competence is based on the knowledge, skills and abilities acquired in the course of training, providing the opportunity to participate in speech communication in its different types: receptive (listening, reading) and productive (speaking, writing). Therefore, the content of communicative competence consists of the following types of competence, such as linguistic (language) competence, which implies a set of knowledge about language elements and the ability to use them to express individual thoughts and comprehend them to others. Moreover, speech competence implies knowledge that is important to express numerous ideas through quite a few language means, which make possible to organize and implement them into a speech action so that to realize communicative intention. In addition, the concept of communicative competence can also include social competence. For instance, desire and ability to enter into communication with other people and discursive competence (knowledge of the rules of constructing a coherent oral and written message - discourse), subject and strategic competence (ability to choose the most effective ways to master the material and use it in solving communicative tasks). All of these types of competence need to be taken into account when creating textbooks, study books, and manuals designed to teach the Russian language to military personnel. Consequently, all texts, tasks, and materials presented in them should be aimed at creating all of the aforementioned competencies. Naturally, the material placed in a textbook should be multi-layered - it should contain linguacultural, social, professional, etc. aspects in addition to purely linguistic information.

Key words: communicative, speech, sociocultural, linguistic competence, conceptual approaches, language families, military 


\section{AUTORIŲ LYDRAŠTIS}

Autoriaus vardas, pavardè: Dileta Jatautaitè

Mokslo laipsnis ir vardas: socialinių mokslų daktarè, docentė

Darbo vieta ir pareigos: Generolo Jono Žemaičio Lietuvos karo akademijos docentè

Autoriaus mokslinių interesų sritys: psicholingvistika, glotoedukologija, edukologija, tradiciniai ir netradiciniai kalbų mokymo metodai bei metodologija, psichoedukologiniai kalbų mokymo ir išmokimo pagrindai

Telefonas ir el. pašto adresas: (8 5) 210 3560; dileta.jatautaite@mil.lt; dileta.jatautaite@1ka.lt

Autoriaus vardas, pavardè: Jelena Kazimianec

Mokslo laipsnis ir vardas: humanitarinių mokslų daktarè, docentė

Darbo vieta ir pareigos: Generolo Jono Žemaičio Lietuvos karo akademijos lektorè

Autoriaus mokslinių interesų sritys: dabartinė rusų kalba, rusų kalbos gramatika, lingvokultūrologija, svetimujų kalbų dėstymo didaktika, sociolingvistika, komparatyvistinè lingvistika

Telefonas ir el. pašto adresas: + 37068759 272; jelena.kazimianec@lka.lt

\section{AUTHORS' COVER LETTERS}

Author's name and surname: Dileta Jatautaitè

Academic degree and name: Associate Professor, Doctor

Workplace and position: General Jonas Žemaitis Military Academy of Lithuania

Author's research interests: psycholinguistics, glotoeducology, neurolinguistics, traditional and non-traditional language teaching methods and methodology, psycho-educational basis in language learning and acquisition

Telephone and e-mail address: +370 5210 3560; dileta.jatautaite@mil.lt; dileta.jatautaite@1ka.lt

Author's name and surname: Jelena Kazimianec

Academic degree and name: Lecturer, Associate Professor, Doctor,

Workplace and position: The General Jonas Žemaitis Military Academy of Lithuania, Associated Professor, lecturer, Doctor

Author's research interests: modern Russian, Russian grammar, and comparative linguistics, foreign language teaching methods, social linguistics, and lingua-culturology.

Telephone and e-mail address: +370 68759 272; jelena.kazimianec@lka.lt 